\title{
Insights into pediatric pollen food allergy syndrome
}

\author{
Jeong Hee Kim, MD
}

Department of Pediatrics, Inha University Hospital, Inha University College of Medicine, Incheon, Korea

Pollen food allergy syndrome (PFAS), previously known as oral allergy syndrome (OAS), is an immunoglobulin E-mediated food allergy caused by cross-reactivity between pollen and plants allergens. Patients with pollen allergies may react to fruits, vegetables, and/or tree nuts that share epitopes of prior sensitized allergenic pollen. ${ }^{1)}$ OAS is a term based on a characteristic clinical manifestation of oropharyngeal symptoms. OAS is primarily caused by plant foods which cross-react with pollen, but it can be caused by animal food allergen. Thus, OAS is currently considered a collection of symptoms of food allergy or latex fruit syndrome in addition to PFAS.

The prevalence of PFAS is difficult to estimate for several reasons including a lack of awareness of patients and physicians. Since the prevalence of pollinosis has increased with climate change, ${ }^{2)}$ the incidence of PFAS is also expected to increase.

Little is known about PFAS prevalence by age. Among British children with seasonal allergic rhinitis (AR), the prevalence of PFAS was reportedly $17 \%$ and $78 \%$ in those under 5 and older than 10 years, respectively. ${ }^{3)}$ This large difference in prevalence is probably due to eating more fruits, vegetables, and/or nuts, and being more aware of symptoms after age 5. Recent study showed no age-based difference in PFAS prevalence among patients with pollen allergies except those under 5 or over 60 years of age. ${ }^{4)}$

The incidence of PFAS in children from some countries was reported as $9 \%-43 \%$, depending on the geographical distribution of types of pollen and the characteristics of study subjects (Table 1). ${ }^{3-8)}$
The prevalence of AR in Korean children is expected to be 21\%; of them, $37.0 \%$ showed pollen sensitization. ${ }^{9)}$ The PFAS prevalence is $42.7 \%$ among Korean children with pollinosis. $\left.{ }^{4}\right)$ This incidence in hospital-based patients may be higher than those of general population. With those data, the estimated prevalence of PFAS would be 3.3\%. Well-known causes of PFAS are birch, alder, timothy grass, orchard grass, mugwort, and ragweed pollen.

Class 1 food allergens, which induce sensitization via the gastrointestinal tract, are stable to heat, acid, and digestive enzymes, and are usually responsible for systemic reactions. Class 2 food allergens are highly cross-reactive with pollen, sensitized through the respiratory route, and generally unstable and degraded easily by heat and digestive enzymes. Symptoms of PFAS include pruritus, paresthesia, and angioedema of the lips, oral mucosa, tongue, and palate. However, other cutaneous, respiratory, gastrointestinal, neurologic, and cardiovascular symptoms and even anaphylaxis may occur at an incidence of 1.9\%-10\%.4) In the current issue, Jeon ${ }^{10)}$ reviewed various PFAS symptoms and their prevalence. Since molecules with high cross-reactivity causing PFAS are ubiquitous, they are classified as panallergens. $\mathrm{Jeon}^{10)}$ also summarized pollens and their cross-reactive allergens of food according to the panallergen family of pathogenesisrelated protein (PR) 10 (PR-10), profiline, and PR-14.

Clinical manifestations can vary depending on sensitized pollen (panallergen) type and implicated food allergens from mild oral symptoms to systemic reactions including anaphylaxis.

Table 1. Prevalence of pediatric pollen food allergy syndrome

\begin{tabular}{|c|c|c|c|c|c|c|}
\hline Country & Subjects, numbers & Age (yr) & Prevalence (\%) & frequently Implicated fruit & Implicated pollen & Comments \\
\hline (taly) & Seasonal AR, 1360 & 4-18 & 24 & Kiwi & Timothy grass & \\
\hline Australia6) & AR with pollen sensitization, 66 & 4-17 & 12 & Watermelon & Perennial rye grass & Sydney region \\
\hline Britain $^{3)}$ & Seasonal AR, 54 & $\begin{array}{c}<5 \\
5-10 \\
>10\end{array}$ & $\begin{array}{l}17 \\
50 \\
78\end{array}$ & Hazelnut, apple, kiwi & Birch & \\
\hline Mexico $^{7)}$ & Seasonal AR, 267 & $6-14$ & 8.9 & Pine apple & Oak & \\
\hline Korea $^{4)}$ & Pollen allergy, 648 & $\leq 18$ & 42.7 & Peach, apple & Birch, alder, oak & \\
\hline Korea $^{8)}$ & AD with birch sensitization, 186 & $\begin{array}{l}2-6 \\
7-18\end{array}$ & $\begin{array}{l}36.6 \\
50.5\end{array}$ & $\begin{array}{l}\text { Kiwi, apple } \\
\text { Apple, kiwi, peach }\end{array}$ & Birch & \\
\hline
\end{tabular}

$A R$, allergic rhinitis; $A D$, atopic dermatitis

Corresponding author: Jeong Hee Kim, MD. Department of Pediatrics, Inha University Hospital, Inha University College of Medicine, 27 Inhang-ro, Jung-gu, Incheon 22332, Korea 
Patients with PFAS reacting to the same food may have different sensitization profiles that result in different responses to food.

Bet v 1 homologues belong to PR-10, well-known causes of OAS, are heat-unstable, thus, elicit mild oropharyngeal symptoms, and account for most of the clinical cross-reactivity between birch pollen and Rosaceae fruits (e.g., apple, pear, plum), Apiaceae vegetables (e.g., celery, carrot), Betulaceae (hazelnut), and Fabaceae (soybean). However, some molecules such as Api g 1 (celery), Ara h 8 (peanut) and Gly $\mathrm{m} 4$ (soybean) can be stable, and cause systemic symptoms. ${ }^{10)}$ Apple, peach and other fruits, as well as peanuts are commonly implicated foods in Bet $\mathrm{v} 1$ sensitized subjects.

Profilins also are ubiquitous, heat-labile, and easily degraded molecules by digestive enzymes, and known to be responsible allergens for the fruit-pollen, fruit-fruit, and latex-food syndrome. Muskmelon (Cuc m 2) has been suggested as a clinical marker of sensitization to profilin. ${ }^{11)}$

Lipid transfer protein (LTP) are members of the family of PR14, resistant to pepsin digestion, and can cause both class I and 2 food allergies. LTP is widely present in a variety of plant foods and pollens, and known to be responsible for allergic reactions to various foods including apple, peach, asparagus, barley, parsley and carrot. Several LTPs are highly cross-reactive among them, thus, LTP-sensitized patients were reported to develop allergic reactions to relevant multiple foods, which is called LTP syndrome. Since Pru $\mathrm{p} 3$ in peach shares epitopes with LTPs from many fruits, nuts and vegetables, and even with mugwort (Art v 3), Pru p 3 was suggested to be a primary sensitizer. ${ }^{12)}$ However, sensitization to LTP without sensitization to Pru $\mathrm{p} 3$ was reported in patients with fruit allergies; kiwi (Act d 10), or pomegranate (Pung 1).

In cases with plant food allergy, such as peach allergy, various reactions can be expected. Some of the subjects with PFAS are associated with birch pollen Bet v 1 (Pru p 1 in PR-10), or birch Bet v2, mugwort and/or grass pollen (Pru 4 in profilin), both of them generally have mild reaction. However, others are caused by LTP (Pru p 3); some of them have multiple allergies to various pollen and plant foods, others to peach only. They will have more severe systemic reactions, including anaphylaxis, especially when the cofactor is present. Therefore, patients with plant food allergy, class 1 , could be diagnosed with OAS, which may lead to suboptimal treatment of potentially life-threatening food allergies.

In conclusion, although the true prevalence of PFAS is difficult to determine in the general pediatric population, PFAS can be present in a significant proportion of children, especially in those with pollen-induced AR. Therefore, it is important to take a detailed medical history in order to diagnose PFAS. Children who are unwilling to eat fruits, vegetables, and/or nuts or having food-associated oropharyngeal symptoms should be evaluated for PFAS. Although many aspects of PFAS remain poorly understood because of great heterogeneity in its causes, risk factors, natural history, comorbidities, and treatment responses, physicians are expected to properly categorize patients and provide appropriate guidance upon understanding the prevalent allergenic pollen and cross-reactive foods by geographical region.

\section{Conflicts of interest}

No potential conflict of interest relevant to this article was reported.

See the article "Pollen-food allergy syndrome in children" via https://doi.org/10.3345/cep.2019.00780.

\section{References}

1. Amlot PL, Kemeny DM, Zachary C, Parkes P, Lessof MH. Oral allergy syndrome (OAS): symptoms of IgE-mediated hypersensitivity to foods. Clin Allergy 1987;17:33-42.

2. Kim SH, Park HS, Jang JY. Impact of meteorological variation on hospital visits of patients with tree pollen allergy. BMC Public Health 2011; 11:890.

3. Ludman S, Jafari-Mamaghani M, Ebling R, Fox AT, Lack G, Du Toit G. Pollen food syndrome amongst children with seasonal allergic rhinitis attending allergy clinic. Pediatr Allergy Immunol 2016;27:134-40.

4. Kim MA, Kim DK, Yang HJ, Yoo Y, Ahn Y, Park HS, et al. Pollen-food allergy syndrome in Korean pollinosis patients: a nationwide survey. Allergy Asthma Immunol Res 2018;10:648-61.

5. Dondi A, Tripodi S, Panetta V, Asero R, Businco AD, Bianchi A, et al. Pollen-induced allergic rhinitis in 1360 Italian children: comorbidities and determinants of severity. Pediatr Allergy Immunol 2013;24:742-51.

6. Brown $\mathrm{CE}$, Katelaris $\mathrm{CH}$. The prevalence of the oral allergy syndrome and pollen-food syndrome in an atopic paediatric population in southwest Sydney. J Paediatr Child Health 2014;50:795-800.

7. Bedolla-Barajas M, Kestler-Gramajo A, Alcalá-Padilla G, MoralesRomero J. Prevalence of oral allergy syndrome in children with allergic diseases. Allergol Immunopathol (Madr) 2017;45:127-33.

8. Kim KI, Lee B, Min TK, Lee J, Pyun BY, Jeon YH. Clinical characteristics of oral allergy syndrome in children with atopic dermatitis and birch sensitization: a single center study. J Korean Med Sci 2019;34:e11.

9. Kim DH, Park YS, Jang HJ, Kim JH, Lim DH. Prevalence and allergen of allergic rhinitis in Korean children. Am J Rhinol Allergy 2016;30:72-8.

10. Jeon YH. Pollen-food allergy syndrome in children. Clin Exp Pediatr 2020;63:463-8.

11. Asero R, Mistrello G, Roncarolo D, Amato S, Zanoni D, Barocci F, et al. Detection of clinical markers of sensitization to profilin in patients allergic to plant derived foods. J Allergy Clin Immunol 2003;112:427-32.

12, Gao Z, Yang Z, Wu S, Wang H, Liu M, Mao W, et al. Peach allergy in China: a dominant role for mugwort pollen lipid transfer protein as a primary sensitizer. J Allergy Clin Immunol 2013;131:224-6.

How to cite this article: Kim JH. Insights into pediatric pollen food allergy syndrome. Clin Exp Pediatr 2020;63:483-4. https:// doi.org/10.3345/cep.2019.01179 